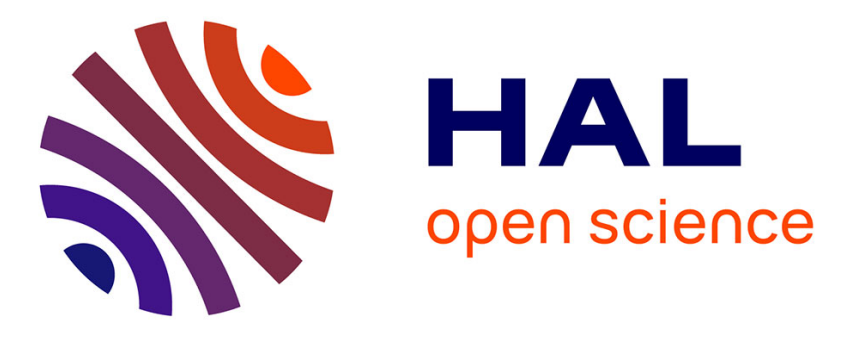

\title{
Crohn's disease: is there any link between anal and luminal phenotypes?
}

\author{
Timothée Wallenhorst, Charlène Brochard, Jean-François Bretagne, \\ Guillaume Bouguen, Laurent Siproudhis
}

\section{- To cite this version:}

Timothée Wallenhorst, Charlène Brochard, Jean-François Bretagne, Guillaume Bouguen, Laurent Siproudhis. Crohn's disease: is there any link between anal and luminal phenotypes?. International Journal of Colorectal Disease, 2016, 31 (2), pp.307-311. 10.1007/s00384-015-2390-8 . hal-01207283

\section{HAL Id: hal-01207283 \\ https://hal-univ-rennes1.archives-ouvertes.fr/hal-01207283}

Submitted on 15 Jan 2016

HAL is a multi-disciplinary open access archive for the deposit and dissemination of scientific research documents, whether they are published or not. The documents may come from teaching and research institutions in France or abroad, or from public or private research centers.
L'archive ouverte pluridisciplinaire HAL, est destinée au dépôt et à la diffusion de documents scientifiques de niveau recherche, publiés ou non, émanant des établissements d'enseignement et de recherche français ou étrangers, des laboratoires publics ou privés. 


\section{Crohn's disease: is there any link between anal and luminal phenotypes?}

Timothée Wallenhorst (1) $_{\text {Charlène Brochard }}^{\text {(1) (2) (3) Jean-François Bretagne }}{ }^{\text {(1) (2) }}$ Guillaume Bouguen ${ }^{(1)(2)(3)}$ Laurent Siproudhis (1) (2) (3)

1. Department of Hepato-Gastroenterology, University Hospital of Rennes, Service des Maladies de l'Appareil Digestif, CHU, Pontchaillou, 2 rue Henri le Guilloux, 35033 Rennes Cedex, France

2. INSERM U991, University of Rennes 1, Rennes, France

3. CIC1414 University Hospital of Rennes, Pontchaillou, France

\section{Abstract}

\section{Purpose}

Perianal Crohn's disease (CD) encompasses a variety of lesion similar to luminal disease, which are usually not distinctly assessed. Links between luminal and perianal CD phenotype remains therefore underreported, and we aimed to describe both luminal and perianal phenotype and their relationships.

\section{Methods}

From January 2007, clinical data of all consecutive patients with CD seen in a referral center were prospectively recorded. Data recorded until October 2011 were extracted and reviewed for study proposal.

\section{Results}

A total of 282 patients $(\mathrm{M} / \mathrm{F}, 108 / 174$; aged $37.8 \pm 16.2$ years $)$ were assessed that included 154 cases $(54.6 \%)$ with anal ulceration, 118 cases $(41.8 \%)$ with fistula, 49 cases $(17.4 \%)$ with stricture, and 94 cases without anal lesion (33.3\%). Anal ulcerations were associated with fistulas $(N=87 / 154)$ in more than half of patients $(56.5 \%)$ and were isolated in 55 patients $(35.7 \%)$. Most of strictures (94\%) were associated with other lesions $(N=46 / 49)$. Harvey-Bradshaw score was significantly higher in patients with ulcerations $(p<0.001)$ as compared to those with perianal fistulas $(p=0.15)$ or with anal strictures $(p=0.16)$. Proportions of complicated behavior (fistulizing or stricturing) of luminal CD were similar according to anal lesions: anal fistulas were not significantly associated to penetrating Montreal phenotype $(N=4 / 31 p=0.13)$ as well as anal stricture and stricturing Montreal phenotype $(N=3 / 49, p=0.53)$.

\section{Conclusions}

The phenotype of luminal disease does not link with the occurrence and the phenotype of perianal Crohn's disease. Anal ulcerations denote a more severe disease on both luminal and perianal locations and should consequently be taking into account in physician decisionmaking. 


\section{Keywords}

Crohn's disease Perianal Crohn's disease Anal ulceration Epidemiology

\section{Introduction}

In spite of their frequency, perianal lesions were not mentioned as a feature of Crohn's disease (CD) in the initial description and were only recognized as such 30 years later [1]

Perianal Crohn's disease (PCD) encompasses fistulizing lesions including perianal fistulas and abscesses and non-fistulizing lesions such as ulcerations, strictures, or skin tags [2-4]. PCD is one of the most dreaded complications of CD leading to anal pain, discharge, dyschezia, and fecal incontinence in addition to emotional symptoms and impairment of social and sexual functioning that significantly alter the quality of life of patients $[4,5]$. Moreover, PCD independently denotes a more aggressive and disabling CD phenotype $[6,7]$.

According to European guidelines, use of the Montreal classification is advocated in order to better define and treat CD [8]. In this classification, PCD is summarized to a " $p$ " whereas prognosis and significance may vary according to the type of perianal lesions. Both physicians and surgeons are aware of anal fistulas and abscesses. In contrast, anal strictures, ulcers, and anal phenotypes are underreported in both studies and guidelines and consequently are not taken into account in prognosis and treatment strategies despite an easy access to their diagnosis.

It remains unclear whether fistulizing or non-fistulizing or both PCD behaviors affect overall disease outcomes. The aim of the study was therefore to describe both luminal and perianal phenotypes in a prospective cohort of subjects suffering from Crohn's disease as well as relationship between the two localizations.

\section{Methods}

\section{Study population}

All hospital records of consecutive patients suffering from $\mathrm{CD}$, followed in a French referral center for inflammatory bowel disease and proctology, University Hospitals of Rennes, France, between January 2007 and October 2011, were reviewed. All patients with an established diagnosis of CD based on clinical, biological, radiological, endoscopic, and/or histological evidence were prospectively enrolled in a registry and followed up.

The following data were prospectively recorded in a secure database: sex, age, size, weight, CD phenotype according to the Montreal classification [9], and treatment (including steroids, 5-ASA, immunosuppressives, TNF antagonists, and miscellaneous treatment).

At each clinic and for each patient, CD activity was evaluated by using the Harvey-Bradshaw score [10], anatomical classification of PCD was described according to the Cardiff classification (including a digital examination) [11], and PCD activity was evaluated with the Perianal Disease Activity Index (PDAI) [12]. 
To supplement data from the registry for study purpose, the following clinical data were extracted from chart review of patients: age at diagnosis, Montreal CD classification at diagnosis, previous medications, and history of abdominal and anal surgery.

According to Harvey-Bradshaw score (HBS), CD was considered in clinical remission when HBS was below 4, mild to moderately active when HBS ranged from 4 to 12, and severely active with a HBS above 12 .

Although elementary PCD lesions are usually described separately, they are often associated at an individual level. Anal strictures were mostly associated to other PCD lesions (e.g., ulceration and/or fistula) and were not separately analyzed. Thus, the population of the study was separated into four groups based on their anal phenotype:

- Ulceration phenotype: anal ulceration without fistula

- Mixed phenotype: anal ulceration associated with fistula

- Fistula phenotype: fistula without anal ulceration

- Control group: neither ulceration, nor fistula

\section{Statistical analysis}

Quantitative variables were described as mean \pm standard deviation (SD). All analysis and data were performed on the patient at the time of their first management in our center. Categorical variables were presented as counts and percent of the cohort. The non-parametric Wilcoxon signed-rank test for continuous variable and the non-parametric Pearson test for categorical variable were used to compare disease characteristics according to elementary PCD lesions and according to anal phenotype. Statistical analyses were performed using JMP ${ }^{\circledR}$ Pro 9.0.2 software.

\section{Ethical considerations}

The study was approved by the Hospital Ethics Committee and the "Commission Nationale Informatique et Liberté" (CNIL n 1412467).

\section{Results}

\section{Characteristics of the population}

Data of 282 consecutive CD patients (M/F, 108/174, aged $37.8 \pm 16.2$ years) were prospectively recorded during the study period: 154 patients $(54.6 \%)$ had anal ulceration (superficial ulcer U1, 77; cavitating ulcer U2, 77), 118 patients $(41.8 \%)$ had fistula (superficial fistula F1, 33; high and/or complex fistula F2, 85), 49 patients (17.4\%) had stricture (short stricture S1, 32; long stricture S2, 17), and 94 patients had no PCD (33.3\%). The mean duration of $\mathrm{CD}$ was $8.2 \pm 7.3$ years, and the mean duration of anal symptoms was $1.8 \pm 3.2$ years. Previous anal surgery for fistulas was performed in 110 patients $(39 \%)$. Ileal resections $(N=21 ; 7.5 \%)$, ileocolectomy $(N=38 ; 13.5 \%)$, partial colectomy $(N=5 ; 2.5 \%)$, and total colectomy $(N=12 ; 4.3 \%)$ were previously reported in 76 patients $(26.6 \%)$. AntiTNF treatment has been instituted in 183 patients $(64.9 \%)$, for a mean duration of $2.1 \pm 2.8$ years: $122(43.3 \%), 43(15.2 \%)$, and $18(6.3 \%)$ subjects before, during, and after referral, respectively. In fact, 102 patients had previous biologics at referral and 75 underwent 
an intestinal resection at referral. This may bias the analysis. Infliximab was the most often used biologics $(N=109 ; 59.6 \%)$ compared with adalimumab $(N=44 ; 24 \%)$.

Thiopurines and methotrexate were used in $148(52.4 \%)$ and $34(12.1 \%)$ patients, respectively. Regarding luminal CD, 127 patients (45\%) were in remission according to the HBS $(<4), 118$ patients $(41.9 \%)$ had mild to moderate disease activity (HBS score from 4 to $12)$, and 37 patients $(13.1 \%)$ suffered from severe active disease (HBS $>12)$.

\section{Elementary anal lesions}

Figure 1 shows associations of elementary fistulizing and non-fistulizing anal lesions in CD. Anal ulcerations were associated with fistulas $(N=87 / 154)$ in more than half of the cases $(56.5 \%)$ and were isolated $(N=55 / 154)$ in one third $(35.7 \%)$ of patients. Strictures were mainly $(94 \%)$ associated with other lesions $(N=46 / 49)$. Above 188 patients who experienced PCD, $14.9 \%(N=28 / 188)$ had an association of ulceration, fistula, and stricture. As expected, PDAI index significantly increased with the severity of anal ulcerations (U0, $0.8 \pm 2.4 ; \mathrm{U} 1,6.4 \pm 4.7 ; \mathrm{U} 2,9.7 \pm 4.8 ; p<0.001)$, fistulas (F0, $2.6 \pm 4.1 ; \mathrm{F} 1,7.2 \pm 4.7 ; \mathrm{F} 2$, $8 \pm 5.7 ; p<0.001)$, and strictures (S0, $4 \pm 5.1 ; \mathrm{S} 1,8.3 \pm 5.1 ; \mathrm{S} 2,7.7 \pm 6 ; p<0.001)$.

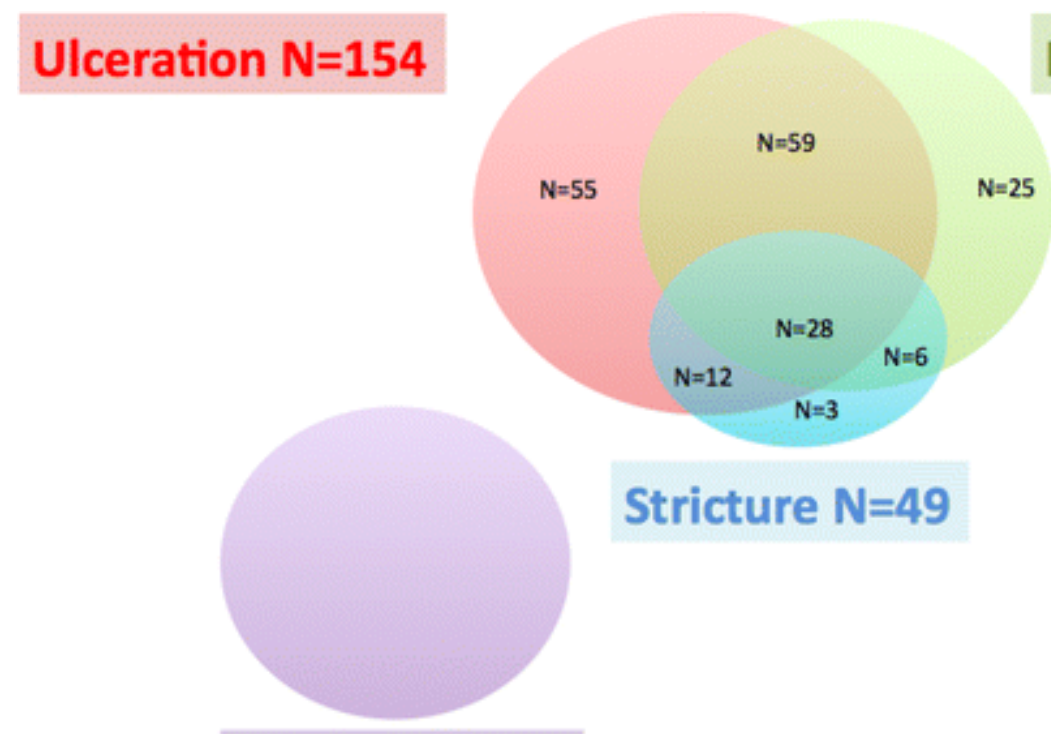

No UFS $\mathrm{N}=94$

\section{Fistula $\mathrm{N}=118$}

\section{$\mathbf{N}=\mathbf{2 8 2}$}

Fig. 1

Distribution of perianal lesions in the population study, according to Cardiff classification (UFS ulceration-fistula-stricture)

Patients with anal ulceration had a shorter CD disease duration as compared to those without ulceration (U0, $9.4 \pm 7.5 ; \mathrm{U} 1,7.9 \pm 6.9 ; \mathrm{U} 2,6.5 \pm 6.8$ years; $p<0.001)$.

\section{Overall CD characteristics according to perianal lesions}

Regarding elementary lesion, the body mass index (BMI) was lower in the presence of ulceration (U0, $24.9 \pm 5.9 ; \mathrm{U} 1,21.3 \pm 4.2 ; \mathrm{U} 2,21.9 \pm 4 ; p<0.001)$. Such differences were not encountered in patients with fistulas (F0, 23.4 $\pm 5.3 ; \mathrm{F} 1,22.7 \pm 4.7 ; \mathrm{F} 2,21.9 \pm 4.3 ; p=0.29)$ or 
those with strictures (S0, 23.1 $\pm 5.3 ; \mathrm{S} 1,21.5 \pm 3.7$; S2, $22.1 \pm 4.2 ; p=0.29)$. HarveyBradshaw score was significantly higher in patients with ulcerations (U0, 3.7 \pm 3.5 ; U1, $6.6 \pm 4.7 ; \mathrm{U} 2,8.0 \pm 5.2 ; p<0.001)$. Such differences were not encountered in patients with fistulas (F0, $5.3 \pm 4.7 ; \mathrm{F} 1,6.7 \pm 5.1 ; \mathrm{F} 2,5.8 \pm 4.5 ; p=0.15)$ or those with strictures (S0, $5.4 \pm 4.8 ; \mathrm{S} 1,6.3 \pm 4.2 ; \mathrm{S} 2,8.9 \pm 5.1 ; p=0.16)$.

\section{Anal phenotypes}

The baseline characteristics of the population according to their main anal phenotype are listed in Table 1. Again, Montreal phenotypes of luminal disease at diagnosis were not significantly different between the various phenotypes of PCD. Fistula or mixed statuses were not significantly associated to penetrating Montreal phenotype (B3) $(N=4 / 31$ and $N=16 / 87$, respectively, $p=0.13)$. No association was found between anal stricture and stricturing Montreal phenotype (B2) $(N=3 / 49, p=0.53)$. No anatomical association was found between the anal and the luminal location phenotype (L phenotype; $p=0.37$ ). As compared to fistula phenotype and control groups, both ulceration and mixed phenotypes had a more severe luminal activity, as highlighted by a higher Harvey-Bradshaw score and a lower body mass index. As compared to fistula phenotype, these two groups had also a more severe anal disease as assessed by PDAI and biologics were more frequently used. Finally, the prevalence of stricture was significantly higher in those with mixed anal lesions.

Table 1

Baseline characteristics of the population according to anal phenotype

\section{CD characteristics}

Mean age (years) $(\mathrm{m} \pm \mathrm{SD})$
Disease duration $(\mathrm{m})(\mathrm{m} \pm$
Body mass index $\left(\mathrm{kg} / \mathrm{m}^{2}\right)$

$(\mathrm{m} \pm \mathrm{SD})$

Montreal classification at diagnosis, $n(\%)$

$9(13.4)$
$57(85.1)$
$7(8.9)$
$7(8.9)$

Treatments, $n(\%)$

No anti-TNF

Anti-TNF initiation

Previous/current/after

Prior intestinal resection

$26 / 18 / 10$

$10(14.9)$

Luminal disease activity

Liquid stool frequency

$(\mathrm{m} \pm \mathrm{SD})$

Harvey-Bradshaw score (HBS) $7.4 \pm 5.3$

\section{Anal phenotype}

\section{Ulcerations \\ Mixed \\ Fistulas}

$(N=87)$

$(N=31)$

\section{No PCD}

$(N=94) \quad$ value

$35 \pm 17$

$34.3 \pm 16$

$39.3 \pm 12$

$40.1 \pm 2<0.05$

$90 \pm 98$

$145 \pm 120$

$115 \pm 90$

$<0.05$

$21.6 \pm 4.3$

$24.3 \pm 4.3$

$25.1 \pm 6.3$

0.001 


\section{CD characteristics}

at inclusion $(\mathrm{m} \pm \mathrm{SD})$

HBS $<4, n(\%)$
HBS [4-12], $n(\%)$
HBS $>12, n(\%)$

Anal disease activity

PDAI $(\mathrm{m} \pm \mathrm{SD})$

$6.1 \pm 4.4$

Anal stricture, $\quad n(\%)$

\section{Ulcerations \\ $(N=67)$}

$\begin{array}{ll}25(28.7) & 23(74.2) \\ 46(52.9) & 1(3.2) \\ 16(18.4) & 7(22.6)\end{array}$

$59(60.8)$

0.0001

$16(18.4)$

0.0001

$5(5.2)$

0.0001

$\begin{array}{cc}\text { No PCD } & p \\ (N=94) & \text { value }\end{array}$

$C D$ Crohn's disease, $P C D$ perianal Crohn's disease, $A 1$ age at diagnosis below 16 years, $B 1$ non-stricturing non-penetrating behavior, $L 1$ ileal location, $L 4$ isolated upper disease location, HBS Harvey-Bradshaw score, TNF tumor necrosis factor, PDAI Perianal Disease Activity Index

\section{Discussion}

Patients of this prospectively recorded database were assessed using recommended classifications and validated scales [8, 13]. Both fistula and non-fistula lesions of PCD were carefully recorded with an equal interest. Similarly to the Montreal classification of the luminal disease, different anal phenotypes have been described. The main strengths are the duration of follow-up (about 5 years), the management of patients with a standardized monitoring using validated scales, and the prospective assessment. However, this retrospective study has several limitations. Proctitis was not recorded in the database, and consequently, the impact of active proctitis could not be assessed. Because this study was performed in a tertiary referral center, the effects of TNF $\alpha$ antagonists remain difficult to interpret because of the large number of patients treated with TNF $\alpha$ prior to and after the diagnosis of anoperineal lesions. The classifications were obtained from the first physical examination in the referral center. Thus, some patients had a previous history of anti TNF medication and/or intestinal resection. In fact, 102 patients had previous biologics at referral and 75 underwent an intestinal resection at referral. This may bias the analysis.

The high prevalence of anal lesions in accordance with previous reported experience of fistulas may not only be related to this careful assessment but it also reflects the recruitment of a tertiary center $[6,14,15]$. Thus, the systematic prospective recording of elementary lesions and their associations are the key points rather than the incidence of anal lesions.

In fact, anal ulcerations were more frequent than previously reported [6, 14, 16-21]. This result suggests that anal ulcerations could be underdiagnosed because of the lack of perianal assessment during follow-up of patients. Given the impact of PCD lesions, practitioners should pay particular attention to the occurrence of anal ulceration since it may represent a clinical marker of an active Crohn's disease. In the present study, patients with anal ulcerations had higher symptomatic scores in the assessment of both anal (PDAI) and luminal (Harvey-Bradshaw score, BMI) activity of Crohn's disease. This may represent a noninvasive marker of follow-up which may be prospectively tested in patients with anal ulcerations. Biologics are currently more used in this group. This concept was pointed out before the era of biologics in another cohort of anal lesion of CD [6]. From a clinical point of 
view, biologics may be used to treat anal ulceration but an evaluation of such a therapeutic strategy cannot be recommended without a prospective randomized evaluation which is lacking.

In fact, patients with anal fistulas did not show any similar association with luminal activity since Harvey-Bradshaw scores did not significantly differ as compared to those with no anal lesion. In contrast to anal ulceration, biologics are recommended to treat drained fistulas with a better level of evidence [22].

Although anal and luminal phenotype share similar anatomical classification, we did not find any link between them in the present series. There was no significant association between the occurrence of perianal fistula or anal stricture and B2 or B3 Montreal phenotype. From a clinical point of view, this lack of association is important and the physician cannot consider a B2 phenotype in a patient with an anal fistula. We can speculate that the natural history of internal fistulas is different from that of anal fistulas.

A significant association between PCD and intestinal fistulas was reported in a previous series [23]. Ileal disease was identified as predictive factor of perianal surgery elsewhere [24]. However, the nature of the anal lesions was not detailed in these two experiences.

Of note, PCD fistulas carried a higher risk of anal stricture. No significant association has been observed between anal stenosis and disease activity (data not shown). Anal stricture does not remain a healing scare with non-reversible consequence since it is associated to inflammatory processes such as ulceration and fistulas. In fact, biologics may improve and reverse this condition [25].

In conclusion, our results indicate that the phenotype of luminal disease does not link with the occurrence and the type of anal lesion of CD. For this reason, it is reasonable to add a specific description of anal phenotype to the Montreal classification. The main reason is that anal ulcerations carry a pertinent clinical impact of a more severe disease on both luminal and perianal locations and could impact physician in decision-making.

\section{Acknowledgment}

None.

\section{Authors' contributions}

TW, GB, and LS were involved in the study design, interpretation, and analysis of data and edited the manuscript. TW performed the collection of data. LS performed the statistical analysis. All authors reviewed the paper and approved the final submitted draft.

\section{Compliance with ethical standards}

\section{Conflict of interest}

The authors declare that they have no competing interests.

\section{Source of funding}


JFB has received lecture fees from Abbott Laboratories, Ferring, and MSD Pharma.

GB has received lecture fees from Abbott Laboratories, Ferring, and MSD Pharma.

\section{Grant support}

This work did not receive any financial support.

\section{References}

1. Crohn B, Ginzburg L, Oppenheimer G (1932) Regional ileitis: a pathologic and clinical entity. J Am Med Assoc 99:1323-1329CrossRef

2. Sandborn WJ, Fazio VW, Feagan BG et al (2003) AGA technical review on perianal Crohn's disease. Gastroenterology 125:1508-1530CrossRefPubMed

3. Bonheur JL, Braunstein J, Korelitz BI et al (2008) Anal skin tags in inflammatory bowel disease: new observations and a clinical review. Inflamm Bowel Dis 14:12361239CrossRefPubMed

4. Bouguen G, Siproudhis L, Bretagne JF et al (2010) Nonfistulizing perianal Crohn's disease: clinical features, epidemiology, and treatment. Inflamm Bowel Dis 16:14311442CrossRefPubMed

5. Mahadev S, Young JM, Selby W et al (2011) Quality of life in perianal Crohn's disease: what do patients consider important? Dis Colon Rectum 54:579_ 585CrossRefPubMed

6. Siproudhis L, Mortaji A, Mary JY et al (1997) Anal lesions: any significant prognosis in Crohn's disease? Eur J Gastroenterol Hepatol 9:239-243CrossRefPubMed

7. Beaugerie L, Seksik P, Nion-Larmurier I et al (2006) Predictors of Crohn's disease. Gastroenterology 130:650-6CrossRefPubMed

8. Van Assche G, Dignass A, Reinisch W et al (2010) The second European evidencebased consensus on the diagnosis and management of Crohn's disease: special situations. J Crohns Colitis 4:63-101CrossRefPubMed

9. Satsangi J, Silverberg MS, Vermeire S et al (2006) The Montreal classification of inflammatory bowel disease: controversies, consensus, and implications. Gut 55:749753PubMedCentralCrossRefPubMed

10. Harvey RF, Bradshaw JM (1980) A simple index of Crohn's disease activity. Lancet 1:514CrossRefPubMed

11. Hughes LE (1978) Surgical pathology and management of anorectal Crohn's disease. J R Soc Med 71:644-651PubMedCentralPubMed

12. Irvine EJ, McMaster IBD, Group S (1995) Usual therapy improves perianal Crohn's disease as measured by a new disease activity index. J Clin Gastroenterol 20:2732CrossRefPubMed

13. Lichtenstein GR, Hanauer SB, Sandborn WJ (2009) Management of Crohn's disease in adults. Am J Gastroenterol 104:465-83CrossRefPubMed

14. Fleshner PR, Schoetz DJ Jr, Roberts PL et al (1995) Anal fissure in Crohn's disease: a plea for aggressive management. Dis Colon Rectum 38:1137-1143CrossRefPubMed

15. Bouchard D, Denis J (1999) Anoperineal Crohn's disease. Acta Endoscop 29:283301CrossRef

16. Sangwan YP, Schoetz DJ, Murray DJ et al (1996) Perianal Crohn's disease. Results of local surgical treatment. Dis Colon Rectum 39:529-535CrossRefPubMed

17. Sweeney JL, Ritchie JK, Nicholls RJ et al (1988) Anal fissure in Crohn's disease. Br J Surg 75:56-57CrossRefPubMed 
18. Williams DR, Coller JA, Corman ML et al (1981) Anal complication in Crohn's disease. Dis Colon Rectum 24:22-24CrossRefPubMed

19. Keighley MR, Allan RN (1986) Current status and influence of operation on perianal Crohn's disease. Int J Colorectal Dis 1:104-107CrossRefPubMed

20. Wolff BG, Cup CE, Beart RW Jr et al (1985) Anorectal Crohn's disease: a long-term perspective. Dis Colon Rectum 28:709-711CrossRefPubMed

21. Eglinton TW, Barclay LM, Gearry RB et al (2012) The spectrum of perianal Crohn's disease in a population-based cohort. Dis Colon Rectum 55:773-777CrossRefPubMed

22. Gecse KB, Bemelman W, Kamm MA, Stoker J, Khanna R et al (2014) A global consensus on the classification, diagnosis and multidisciplinary treatment of perianal fistulising Crohn's disease. Gut 63:1381-92CrossRefPubMed

23. Sachard DB, Bodian CA, Goldstein ES et al (2005) Is perianal Crohn's disease associated with intestinal fistulization? Am J Gastroenterol 100:1547-1549CrossRef

24. Eglinton TW, Reilly M, Chang C et al (2010) Ileal disease is associated with surgery for perianal disease in a population-based Crohn's disease cohort. Br J Surg 97:11031109CrossRefPubMed

25. Brochard C, Siproudhis L, Wallenhorst T, Cuen D, d'Halluin PN et al (2014) Anorectal stricture in 102 patients with Crohn's disease: natural history in the era of biologics. Aliment Pharmacol Ther 40:796-803CrossRefPubMed 